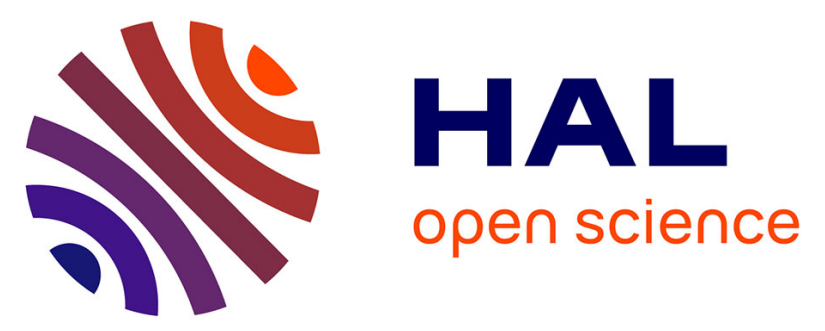

\title{
Added value of [(18)F]fluorodeoxyglucose positron emission tomography/computed tomography for the diagnosis of post-operative instrumented spine infection
}

\author{
E. Follenfant, N. Balamoutoff, Sylvie Lawson-Ayayi, H. Dutronc, M. Dupon, \\ J. M. Vital, P. Delobel, H. Durox, H. de Clermont-Gallerande, P. Fernandez, \\ et al.
}

\section{To cite this version:}

E. Follenfant, N. Balamoutoff, Sylvie Lawson-Ayayi, H. Dutronc, M. Dupon, et al.. Added value of [(18)F]fluorodeoxyglucose positron emission tomography/computed tomography for the diagnosis of post-operative instrumented spine infection. Joint Bone Spine, 2019, 86 (4), pp.503-508. 10.1016/j.jbspin.2019.01.009 . hal-03209245

\section{HAL Id: hal-03209245 \\ https://hal.science/hal-03209245}

Submitted on 25 Oct 2021

HAL is a multi-disciplinary open access archive for the deposit and dissemination of scientific research documents, whether they are published or not. The documents may come from teaching and research institutions in France or abroad, or from public or private research centers.
L'archive ouverte pluridisciplinaire HAL, est destinée au dépôt et à la diffusion de documents scientifiques de niveau recherche, publiés ou non, émanant des établissements d'enseignement et de recherche français ou étrangers, des laboratoires publics ou privés.

\section{다)(1) $\$$}

Distributed under a Creative Commons Attribution - NonCommerciall 4.0 International 


\section{Added value of $\left[{ }^{18} \mathrm{~F}\right]$ fluorodeoxyglucose positron emission tomography/computed tomography for the diagnosis of post-operative instrumented spine infection}

Emilie Follenfant ${ }^{1,2}$, Nicolas Balamoutoff ${ }^{2,3,4}$, Sylvie Lawson-Ayayi ${ }^{5}$, Hervé Dutronc ${ }^{1,2}$, Michel Dupon $^{1,2}$, Jean-Marc Vital ${ }^{2,6}$, Pierre Delobel ${ }^{2,7}$, Hélène Durox ${ }^{2,8}$, Henri de ClermontGallerande $^{2,3,4}$, Philippe Fernandez $z^{2,3,4}$, Frédéric-Antoine Dauchy ${ }^{1,2,5}$

1- Department of Infectious and Tropical Diseases, Hôpital Pellegrin, CHU de Bordeaux, 33076 Bordeaux, France

2- Centre de Référence Infections Ostéo-Articulaires Complexes du Grand Sud-Ouest (Crioac GSO), 33076 Bordeaux, France

3- Service de Médecine Nucléaire, Hôpital Pellegrin; 33076 Bordeaux, France

4- INCIA, UMR, CNRS 5287, Université de Bordeaux, 33076 Bordeaux, France

5- INSERM U1219 Bordeaux Population Health, ISPED, University of Bordeaux, 33076 Bordeaux, France.

6- Spine Unit One, Orthopaedic Surgery, Hôpital Pellegrin, CHU de Bordeaux, Bordeaux, France

7- Department of Infectious and Tropical Diseases, CHU de Toulouse, Toulouse, France

8- Department of Infectious and Tropical Diseases, CHU de Limoges, Limoges, France.

Corresponding author: Frédéric-Antoine Dauchy, Department of Infectious and Tropical Diseases, Hôpital Pellegrin, CHU de Bordeaux, Place Amélie Raba-Leon 33076 Bordeaux, France

frederic.dauchy@chu-bordeaux.fr ; Tel +33 0556795536 


\section{Abstract}

Purpose: Post-operative instrumented spine infection (PISI) is an infrequent complication. Diagnosis of spinal implant infection can be difficult, especially in case of chronic infection.

Methods: This retrospective study attempts to evaluate the diagnostic performance of $\left[{ }^{18} \mathrm{~F}\right]$ fluorodeoxyglucose positron emission tomography/computed tomography (PET/CT) in PISI. Imagings were performed between April 2010 and June 2018 among patients referred for suspected chronic spinal implant infection. PET/CT were performed more than 12 weeks after surgery. PET/CT images were re-interpreted independently by two nuclear medicine physicians without knowledge of the patient's conditions. PET/CT data were analyzed both visually and semi-quantitatively $\left(S U V_{\max }\right)$. MRI results were collected from medical records. The final diagnosis of infection was based on bacteriological cultures or a twelve-month follow-up.

Results: Forty-nine PET/CT were performed in 44 patients (22 women, median age 65.0 years). Twenty-two patients had a diagnosis of infection during follow-up. Sensitivity, specificity, positive predictive value (PPV) and negative predictive value (NPV) for PET/CT were $86.4 \%, 81.5 \%, 79.2 \%$, and $88.0 \%$. Sensitivity, specificity, PPV and NPV were $66.7 \%$, $75.0 \%, 66.0 \%, 75.0 \%$ respectively for $\mathrm{MRI}$ and $50.0 \%, 92.6 \%, 84.6 \%$ and $69.4 \%$ for serum C-reactive protein (CRP). Although these values were higher for PET/CT than for MRI or CRP, the differences were not statistically significant. In this setting, false positives with $\mathrm{PET} / \mathrm{CT}$ can be observed in case of previous spine infection or adjacent segments disc disease. False negatives can result of extensive instrumented arthrodesis or infection with low virulence bacteria.

Conclusion: PET/CT is useful for the diagnosis of PISI. These results should be evaluated in further prospective study.

Keywords: $\left[{ }^{18} \mathrm{~F}\right]$ fluorodeoxyglucose positron emission tomography/computed tomography, implant, spine infection. 


\section{Introduction}

Post-operative instrumented spine infection (PISI) is an infrequent complication with a mean incidence $2-3 \%$ [1]. This incidence figure vary between $0.2 \%$ and $6.7 \%$ depending on the type of underlying pathology, on the complexity of the surgery and on the extend of the implanted material. PISI is associated with a high morbidity and a mortality rate up to $10 \%$ [2]. The optimal therapeutic management requires an experimented multidisciplinary team [3]. The surgical treatment of a chronic spinal implant infection can be technically complex and is at risk of inducing complications. Thus, it is essential to carry out precise diagnosis before surgery [4]. The diagnostic criteria are essentially based on the microbiology [3] as the clinical and biological features of the patient can be not conclusive. Unfortunately, culture on deep biopsy samples can rarely be obtained before surgery [5], and blood cultures are of low relevance in this affection [6]. Concerning biological assessment, serum C-reactive protein (CRP) dosage is the most reliable test. Nevertheless, CRP lacks sensitivity in the chronic stage of implant infection $[4,7,8]$ and the diagnosis usually requires alternative tools as imaging. Magnetic resonance imaging (MRI) is considered the gold standard for the diagnosis of spine infection [8]. MRI presents a sensitivity and a specificity close to $67 \%$ and 84\% [9]. However, MRI has strong limitations in PISI. Indeed, within months after the surgery, MRI can hardly differentiate infection from ongoing reparative tissue processes [10]. Furthermore, numerous artifacts due to the metallic implants do prevent a quality performance of the analysis [9]. In the literature, $\left[{ }^{18} \mathrm{~F}\right]$ fluorodeoxyglucose positron emission tomography/computed tomography (PET/CT) has shown excellent diagnostic performances for the detection of spinal infection, with a sensitivity between $86-100 \%$ and specificity 65 $100 \%$ [11-19]. Other nuclear medicine techniques such as white blood cells scintigraphy are not performing well during spine infections [12]. Data are lacking concerning the value of $\mathrm{PET} / \mathrm{CT}$ for the diagnosis of spinal implant infection. Therefore, we propose to evaluate its diagnostic performance in clinical routine use within the framework of PISI.

\section{Methods}

\subsection{Patients}

We conducted a retrospective observational study taking into account adult patients with a suspected chronic spinal infection with implanted material who underwent a PET/CT 
between $1^{\text {st }}$ April 2010 and $16^{\text {th }}$ June 2018. The study was performed in the Department of Infectious and Tropical Diseases of the University Hospital of Bordeaux, a 3000-bed university-affiliated teaching hospital that serves as a referral center for bone and joint infections in southwestern France. This study got an approval from the ethics committee of the University Hospital of Bordeaux (ref. 2018-22). Patients were selected using the French hospital national database codification (PMSI: Programme de Médicalisation du Système d'Information, with ICD10 codes). The data were anonymized and data protection ensured. Inclusion criteria were: age over 16 years and PET/CT performed more than 12 weeks after spine surgery. Exclusion criteria were: active cancer, pregnant or breastfeeding women, other implants than orthopedic devices (intrathecal or epidural catheter, intrathecal pump, implantable neurostimulator). Diabetic patients referred for PET/CT could not proceed with imaging in case of increased serum glucose levels $(\geq 10 \mathrm{mmol} / \mathrm{L})$ upon arrival in the nuclear medicine unit. This infrequent situation implies delaying the examination for a few days.

\subsection{Gold standard}

In our center, patients with this type of clinical situations are routinely followed as out-patients for at least 12 months. The diagnosis of infection was based on the observation of pus surrounding the implant during a new surgery and/or the identification of a microorganism from cultures of bone tissue or blood [20,21]. The bone biopsies could be provided by deep surgical samples or percutaneous biopsies. When the presence of coagulase-negative staphylococci or Cutibacterium acnes was suspected, at least two positive samples were required for a positive diagnosis. Infection was excluded in case of sustained resolution of fever, pain and inflammatory syndrome (C-reactive protein $\leq 10 \mathrm{mg} / \mathrm{L}$ ) after 12 months of follow-up.

\subsection{Imaging}

PET/CT (Discovery Rx, GE Healthcare, WI, USA) were performed in patient fasting for at least six hours and with capillary glycemia lower than $10.0 \mathrm{mmol} / \mathrm{L}$. The acquisition was made 60 minutes after the 18[F]FDG injection, by a hybrid camera GE Discovery Rx. It was acquired by sequential images of one or 2 bed position of 10 minutes each with an $18 \mathrm{~cm}$ wide field of view centered on the region of interest or on the whole body, in 3D mode. The attenuation correction was carried out with a CT scan of 16 pins (140 kV; $40 \mathrm{mAs}$ ). For the study, two nuclear medicine doctors analyzed independently the historical PET/CT records, without prior knowledge of the patients' clinico-biological status. Each of them proceeded to a 
qualitative judgment after visual appreciation of the Maximum Intensity Projection (MIP) of the PET on $360^{\circ}$ in order to affect scores on a scale from 0 to 4: 0 absence of infection, 1 improbable infection, 2 undetermined, 3 likely infection, 4 certain infection. In case of discordance on the interpretation, both practitioners confronted to decide the final decision. For the statistical analysis, examinations classified 3 and 4 were considered as positive. Lecture parameters of PET imaging were studied in a previous paper [13]. Briefly, suggestive signs of infection during PET/CT assessment included: (i) uptake location (linear or disciform uptake pattern in intervertebral disc space with/without involvement of endplates, bone involvement and/or surrounding soft tissue abscesses, involvement of arthrodesis material), (ii) uptake pattern (focal or multifocal, higher uptake in the side with suspected infection than in the contralateral side), (iii) uptake intensity estimated by the ratio of the maximum standardized uptake value $\left(S V_{\max }\right.$ ) in the suspected foci over the SUV $\mathrm{max}_{\max }$ of a considered normal region (for example adjacent disc without abnormality) with a ratio $\geq 2.3$. Both attenuated corrected and non-corrected PET images were reviewed to prevent attenuation artifacts. For the present study, the subsequent step was the semi-quantitative assessment achieved by both practitioners. For an optimal assessment of hyper metabolism in the region of interest $(\mathrm{ROI})$, we calculated a ratio of the $\mathrm{ROI}$ maximum standardized uptake value $\left(S U V_{\max }\right)$ to the vertebra just above SUV $\mathrm{V}_{\max }$. For the statistical analysis, average of the two values was used.

MRIs rachis integra (MRI PHILIPS 1.5T) performed with the following sequences: sagittal sequence balanced in $\mathrm{T} 1$ and $\mathrm{T} 2$, sagittal sequence in $\mathrm{T} 1$ with abolition of the fat after injection of Gadolinium, axial sequence T2 on the level of interest. The analysis of MRIs was made by referring to the radiologists reports at the time of the examination. We considered their conclusion and classified them by a binary score. This binary score differentiates MRI corresponding to the presence of infection, or not.

\subsection{Statistical analysis}

After a descriptive analysis of the population, data from infected cases were compared to data from non-infected cases in univariate analysis. The Receiver Operating Characteristic $(\mathrm{ROC})$ analysis was used to find the SUV $\mathrm{Vax}_{\max }$ ratio cut-off providing an optimal specificity while keeping a good sensitivity. Diagnostic performances of the different evaluation methods were calculated and then compared using ROC curves. A combined evaluation score was then developed based on both visual PET/CT and CRP level. Patients with positive visual PET/CT or $\mathrm{CRP} \geq 60 \mathrm{mg} / \mathrm{L}$ were considered as having infection. Analyses were processed using STATA software (version 9.2, Stata Corporation, College Station, TX, USA). 


\section{Results}

\subsection{Description of the study population}

During the study period, we identified 49 different episodes of suspected infections through $49 \mathrm{PET} / \mathrm{CT}$ performed in 44 patients. Three other patients were not included in the study because of cancer history.

Of these 44 patients, 22 were men (50.0\%) and median age was 65.0 years (25-75 interquartile range [IQR]: 52.0-74.2). Median ages were statistically similar between infected (median 64.0, IQR: 56.5-77.5) and non-infected (median 66.0, IQR: 47.0-73.0) patients $(p=0.18)$. The gender ratio was also balanced in the two groups. Five patients had two different episodes of suspected infection, with a new PET/CT performed during the second episode. Characteristics of the 49 episodes are reported in table 1. Of these 49 episodes, a final diagnosis of implant infection was done in 22 cases and was excluded in 27 cases. The 22 infected cases consisted in a first infection in 9 and a relapse of a previous infection in 13 others. Concerning physical exam features, 10 cases (45.4\%) of the 22 infected patients had fever compared to $3.8 \%$ in non-infected patients $(p=0.001)$. Spinal pain was the most common and nonspecific symptom, representing $84 \%$ of patients. Nineteen of the infected patients (86.4\%) presented back pain. Erythema of the scar was the only local sign that was significantly contributive $(p=0.012)$. It was present in $36.4 \%$ of infected patients compared to $7.4 \%$ of uninfected patients. Two cases presented a fistula and five cases presented flow scare and both were subsequently confirmed as infected.

Forty-two MRI were performed. Seven patients could not have MRI because of contraindication (claustrophobia $n=2$, pacemaker $n=2$ ) or refusal by patients $(n=3)$. The median follow up time was 412 days (IQR: 187-971). None of the patients were lost of followup. During follow-up, 19 patients had bacteriological cultures. The samples were obtained by: spine surgery (16 cases), radio-guided biopsy ( 2 cases) or by blood cultures ( 5 cases, 4 of whom were coupled to surgery). The bacteria found in the infected cases were: Staphyloccocus aureus (6 cases), coagulase-negative staphylococcus (3 cases), Cutibacterium acnes (1 case), Pseudomonas aeruginosa (1 case), Proteus mirabilis and Escherichia coli (1 case), Morganella morganii (1 case) and Enterobacter cloacae (1 case). For the remaining eight infected cases, purulent discharge was observed during surgery without growing bacteria found in cultures. 16S RNA PCR were performed for two of them and were negative. 


\subsection{PET/CT results}

Forty-nine PET/CT were realized in 44 patients. The $49 \mathrm{PET} / \mathrm{CT}$ were re-interpreted independently by two experienced nuclear medicine physicians blinded to the patient's final diagnosis. The concordance of the results of this visual evaluation between the two observers was $87.8 \%$ (kappa coefficient 0.76). Based on this assessment, sensitivity, specificity, positive predictive value (PPV) and negative predictive value (NPV) were $86.4 \%$, $81.5 \%, 79.2 \%$, and $88.0 \%$. Of the $49 \mathrm{PET} / \mathrm{CT}$ studied in this study, three were found to be false negatives and five false positives. During semi-quantitative evaluation, mean SUV $\max$ ratio was 2.1 for infected patient and 1.8 for non-infected patients $(p=0.43)$. Based on ROC curve analysis, a SUV $\mathrm{Vax}_{\max }$ ratio $\geq 2.3$ maximized the diagnostic performance (area under curve $=0.63$ ). Using this cut-off, sensitivity and specificity were $40.9 \%$ and $85.2 \%$ respectively.

Forty-two MRI and 49 serum C-reactive protein (CRP) dosages were performed during the initial evaluation of the 49 episodes (more than 12 weeks after surgery). The most discriminant CRP cut-off value was $60 \mathrm{mg} / \mathrm{L}$ (area under curve $=0.71$ ). Sensitivity specificity, PPV and NPV were 66.7\%, 75.0\%, 66.0\%, 75.0\% respectively for MRI and 50.0\%, 92.6\%, $84.6 \%$ and $69.4 \%$ for CRP. Combining positive visual PET/CT or CRP $\geq 60 \mathrm{mg} / \mathrm{L}$ assessment provided the following results: sensitivity $90.9 \%$, specificity $77.8 \%$, PPV $76.9 \%$ and NPV 91.3\%. Comparisons of the different test to visual PET/CT are reported in table 2.

A sub-group analyze was done according to the number of fused levels. The diagnostic values of visual PET/CT were better when patients have an extension of the implanted material to less than three levels, as reported in table 3. In the sub-group with three or more vertebral levels fixed, combining positive visual PET/CT or CRP $\geq 60 \mathrm{mg} / \mathrm{L}$ assessment provided the following results: sensitivity $86 \%$, specificity $64 \%$, PPV $71 \%$ and NPV $82 \%$.

\section{Discussion}

This study is the first to focus on the interest of 18[F]FDG PET/CT for the diagnosis of spinal implant infection. Spinal infection with implanted material is a diagnostic challenge. Clinical signs are sometimes ambiguous, particularly in case of chronic or late spinal infection [22]. We observed that visual PET/CT has good diagnostic values. PET/CT was at least equivalent to MRI for the diagnosis of PISI. A strength of our study is the evaluation of a 
homogeneous sample of patients under routine clinical management. Thus, our results should be reproducible in the majority of spinal surgery centers.

We found diagnostic values similar to those reported in the literature. Previous study focusing mainly on hematogenous spinal infections found better diagnostic values than in our study $[14,16,23,24]$. Studies which assessed the diagnostic value of PET/CT in postoperative spinal infections found similar diagnostics values to those in our study [13,19]. De Winter et al. found a sensitivity at $100 \%$ and a specificity at $81 \%$ for PET without CT. This elevated sensitivity could be explained by the choice of a low SUVmax ratio threshold to maximize the sensitivity and the lack of contribution of the CT for the morphologic analysis [11]. We agree with Nakahara et al. remarks that PET/CT could be a useful technique to narrow the surgical field for successful less invasive surgery [17].

Some elements are able to guide visual assessment of hypermetabolic foci. First, the topography of metabolic lesions can contribute to patterns of infection. For example, a focus centered on a transpedicular screw is more suspect than a diffuse fixation of the material. This image appreciation is particularly helped by the use of reconstructed sagittal images. Second, the intensity of the metabolism is an important element. The semi-quantitative analysis comes here in support of the visual analysis. In this study, a high SUV ratio has a high specificity $(85.2 \%)$ for the diagnosis of infection. Low sensitivity was likely due to attenuation correction, inter-individual and inter-microbiological metabolic diversity. Third, CT is a capital diagnostic tool to analyze the aspect of the metabolic lesions. Injection of iodinated contrast medium is useful for this CT analysis. Signs of infection in CT (abscess, fluid collection, cortical erosions) reinforce PET analysis (Figure 1).

We found some false positives and some false negatives with PET/CT. To prevent false positives, an analysis of the CT scan is essential to correctly identify degenerative or inflammatory conditions associated with mechanical instability [25]. Material instability can be responsible for metal debris that can create an inflammatory reaction [11]. Diffuse or focal hypermetabolism can also be observed close to the material in patients who present an adjacent segment syndrome. This phenomenon was described previously in the literature and is linked to mechanical stresses [11,13]. We did not observed false positives due to degenerative remodeling or vertebral fusion in this study. This suggests that PET/CT could adequately discriminate between infections and degenerative lesions as reported by Stumpe et al. [24]. In this study, the five false positive cases during visual PET/CT assessment were patients with a previous infection. The question of whether the type of bacteria can influence the immune response and the resulting hyper metabolism in PET/CT is unresolved [13]. It is recognized that the immune system activation to a bacterium is distinct from one individual to another as well as from one type of bacteria to another. In this study, three of the five false positives have had a previous spinal infection with Staphylococcus aureus (S. aureus). $S$. 
aureus can acquire specific virulence such as accessory gene regulator (Agr) system and can be responsible for a particularly strong activation of the immune system [26]. One hypothesis is that this activation could persist and be responsible for false positives at $\mathrm{PET} / \mathrm{CT}$. Two of the three false negative cases concern infections with slow-growing organisms (Cutibacterium acnes and $S$. epidermidis) which could explain the absence of hyper metabolism. In this study, false negative patients also have extended material. The composite score combining PET/CT and CRP allows to improve sensitivity to $86 \%$ in the sub-group with three or more vertebral levels fixed, indicating that clinicians should take into account both PET/CT and CRP results in these very complex cases.

Our study has some limitations. We arbitrarily choose a minimum delay of twelve weeks between surgery and the PET/CT because there is limited data in the literature. In our experience, there is a risk of false positives in the first four to eight weeks after surgery. This optimal delay should be investigated in further dedicated studies. Additionally, we may not have taken into account some elements of the surgery. For example the use of bone morphogenic proteins (BMPs) could be at the origin of inflammatory phenomenon. It would be interesting to study specifically these cases. MRI is considered the current reference standard for detection of spinal infection despite limited diagnostic values [13-15,17], including several months, after surgery [27-29]. The lack of MRI rereading may have led to an underestimation of the interest of PET in our study. In the same way, the sufficiently prolonged duration of a twelve-month follow-up can be questioned. It may have led to underestimate latent infections with subsequent occurrences. Whereas we cannot excluded that this may have been responsible for a potential classification bias, the 12-month delay is often proposed in the literature [3-13]. Some biological markers such as CRP are helpful for spinal infection diagnosis [30]. The interest of other markers should be explored. For example, diagnosis could be enhanced when CRP is combined with IL-6 level, as described during joint infection [31]. Other nuclear medicine techniques such as white blood cells scintigraphy or ${ }^{67} \mathrm{Ga}$ scintigraphy are not performing well during spine infections and are not valuable options in this situation [12,32-35]. PET/CT appears the best nuclear exam to date in term of dosimetry, spatial resolution and diagnosis values [11-19]. Our results suggest that PET/CT is useful for the diagnosis of chronic spinal infection with implanted material. These promising results should be evaluated in further prospective multicentric study.

\section{Acknowledgements}

The authors would like to thank all the patients included in the study.

\section{Disclosure of interest}

The authors declare that they have no competing interest. 


\section{References}

1. Smith JS, Shaffrey CI, Sansur CA, et al. Rates of Infection After Spine Surgery Based on 108,419 Procedures: A Report from the Scoliosis Research Society Morbidity and Mortality Committee. Spine 2011;36:556-63.

2. Gouliouris T, Aliyu SH, Brown NM. Spondylodiscitis: update on diagnosis and management. J Antimicrob Chemother 2010;65:11-24.

3. Société de Pathologie Infectieuse de Langue Française (SPILF), Collège des Universitaires de Maladies Infectieuses et Tropicales (CMIT), Groupe de Pathologie Infectieuse Pédiatrique (GPIP), Société Française d'Anesthésie et de Réanimation (SFAR), Société Française de Chirurgie Orthopédique et Traumatologique (SOFCOT), Société Française d'Hygiène Hospitalière (SFHH) et al. Med Mal Infect 2009;39:74574.

4. Chaudhary SB, Vives MJ, Basra SK, et al. Postoperative Spinal Wound Infections and Postprocedural Diskitis. J Spinal Cord Med 2007;30:441-51.

5. Wille H, Dauchy F-A, Desclaux A, et al. Efficacy of debridement, antibiotic therapy and implant retention within three months during postoperative instrumented spine infections. Infect Dis Lond Engl. 2017;49:261-7.

6. Dufour V, Feydy A, Rillardon L, et al. Comparative study of postoperative and spontaneous pyogenic spondylodiscitis. Semin Arthritis Rheum. 2005;34:766-71.

7. Rosahl SK, Gharabaghi A, Zink PM, et al. Monitoring of blood parameters following anterior cervical fusion. J Neurosurg. 2000;92:169-74.

8. Modic MT, Feiglin DH, Piraino DW, et al. Vertebral osteomyelitis: assessment using MR. Radiology. 1985;157:157-66.

9. Ledermann HP, Schweitzer ME, Morrison WB, et al. MR imaging findings in spinal infections: rules or myths? Radiology. 2003;228:506-14.

10. Carragee EJ. The clinical use of magnetic resonance imaging in pyogenic vertebral osteomyelitis. Spine. 1997;22:780-5.

11. De Winter F, Gemmel F, Van De Wiele C, et al. 18-Fluorine Fluorodeoxyglucose Positron Emission Tomography for the Diagnosis of Infection in the Postoperative Spine. Spine 2003;28:1314.

12. Fuster $\mathrm{D}$, Tomás $\mathrm{X}$, Mayoral $\mathrm{M}$, et al. Prospective comparison of whole-body (18)FFDG PET/CT and MRI of the spine in the diagnosis of haematogenous spondylodiscitis. Eur J Nucl Med Mol Imaging. 2015;42:264-71.

13. Dauchy F-A, Dutertre A, Lawson-Ayayi S, et al. Interest of [18F]fluorodeoxyglucose positron emission tomography/computed tomography for the diagnosis of relapse in patients with spinal infection: a prospective study. Clin Microbiol Infect. 2016;22:43843.

14. Smids C, Kouijzer IJE, Vos FJ, et al. A comparison of the diagnostic value of MRI and ${ }^{18}$ F-FDG-PET/CT in suspected spondylodiscitis. Infection. 2017;45:41-9. 
15. Gratz S, Dörner J, Fischer U, et al. ${ }^{18}$ F-FDG hybrid PET in patients with suspected spondylitis. Eur J Nucl Med Mol Imaging. 2002;29:516-24.

16. Schmitz A, Risse J, Grünwald F, et al. Fluorine-18 fluorodeoxyglucose positron emission tomography findings in spondylodiscitis: preliminary results. Eur Spine J. $2001 ; 10: 534-9$.

17. Nakahara $M$, Ito $M$, Hattori $N$, et al. 18F-FDG-PET/CT better localizes active spinal infection than $\mathrm{MRI}$ for successful minimally invasive surgery. Acta Radiol. 2015;56:829-36.

18. Nanni C, Boriani L, Salvadori C, et al. FDG PET/CT is useful for the interim evaluation of response to therapy in patients affected by haematogenous spondylodiscitis. Eur $\mathrm{J}$ Nucl Med Mol Imaging. 2012;39:1538-44.

19. Schiesser M, Stumpe KDM, Trentz O, et al. Detection of Metallic Implant-associated Infections with FDG PET in Patients with Trauma: Correlation with Microbiologic Results. Radiology. 2003;226:391-8.

20. Osmon DR, Berbari EF, Berendt AR, et al. Diagnosis and Management of Prosthetic Joint Infection: Clinical Practice Guidelines by the Infectious Diseases Society of America. Clin Infect Dis. 2013;56:e1-25.

21. Shen $L$, Jiang $C$, Jiang $R$, et al. Diagnosis and classification in MRI of brucellar spondylitis. Radiol Infect Dis. 2017;4:102-7.

22. van der Bruggen W, Bleeker-Rovers CP, Boerman OC, et al. PET and SPECT in Osteomyelitis and Prosthetic Bone and Joint Infections: A Systematic Review. Semin Nucl Med. 2010;40:3-15.

23. Kälicke T, Schmitz A, Risse JH, et al. Fluorine-18 fluorodeoxyglucose PET in infectious bone diseases: results of histologically confirmed cases. Eur J Nucl Med. 2010; 27:524-8.

24. Stumpe KDM, Zanetti M, Weishaupt D, et al. FDG Positron Emission Tomography for Differentiation of Degenerative and Infectious Endplate Abnormalities in the Lumbar Spine Detected on MR Imaging. Am J Roentgenol. 2002;179:1151-7.

25. Peters $M$, Willems $P$, Weijers $R$, et al. Pseudarthrosis after lumbar spinal fusion: the role of 18F-fluoride PET/CT. Eur J Nucl Med Mol Imaging. 2015;42:1891-8.

26. Schweizer ML, Furuno JP, Sakoulas G, et al. Increased Mortality with Accessory Gene Regulator (agr) Dysfunction in Staphylococcus aureus among Bacteremic Patients. Antimicrob Agents Chemother. 2011;55:1082-7.

27. Ortiz O, Pait TG, McAllister $P$, et al.Postoperative magnetic resonance imaging with titanium implants of the thoracic and lumbar spine. Neurosurgery. 1996;38:741-5.

28. Forrester DM. Infectious spondylitis. Semin Ultrasound CT MRI. 2004;25:461-73.

29. Kwon J-W, Hyun S-J, Han S-H, et al.Pyogenic Vertebral Osteomyelitis: Clinical Features, Diagnosis, and Treatment. Korean J Spine. 2017;14:27-34.

30. Sheikh AF, Khosravi AD, Goodarzi $H$, et al. Pathogen Identification in Suspected Cases of Pyogenic Spondylodiscitis. Front Cell Infect Microbiol. [cited 2018 Apr 18];7. 
31. Ettinger M, Calliess T, Kielstein JT, et al. Circulating Biomarkers for Discrimination Between Aseptic Joint Failure, Low-Grade Infection, and High-Grade Septic Failure. Clin Infect Dis. 2015;61:332-41.

32. Erba PA, Glaudemans AWJM, Veltman NC, et al. Image acquisition and interpretation criteria for 99mTc-HMPAO-labelled white blood cell scintigraphy: results of a multicentre study. Eur J Nucl Med Mol Imaging. 2014;41:615-23.

33. Palestro CJ, Kipper SL, Weiland FL, et al. Osteomyelitis: Diagnosis with 99mTclabeled Antigranulocyte Antibodies Compared with Diagnosis with 111/n-labeled Leukocytes_Initial Experience. Radiology. 2002;223:758-64.

34. Palestro CJ. Radionuclide imaging of osteomyelitis. Semin Nucl Med. 2015;45:32-46.

35. Love C, Patel M, Lonner BS, et al. Diagnosing spinal osteomyelitis: a comparison of bone and Ga-67 scintigraphy and magnetic resonance imaging. Clin Nucl Med. 2000; 25:963-77. 
Table 1: Characteristics of the 49 episodes of suspected infections

\begin{tabular}{|c|c|c|c|c|}
\hline & $\begin{array}{l}\text { Global population } \\
(n=49)\end{array}$ & $\begin{array}{l}\text { Infected } \\
(\mathrm{n}=22)\end{array}$ & $\begin{array}{l}\text { Non Infected } \\
(n=27)\end{array}$ & $\begin{array}{l}p- \\
\text { value }\end{array}$ \\
\hline \multicolumn{5}{|l|}{ Clinical characteristics } \\
\hline $\begin{array}{l}\text { Major comorbidities, } \mathbf{n}(\%) \\
\text { Diabetes mellitus } \\
\text { Cancer } \\
\text { Immunosuppressive treatment / steroids } \\
\text { Chronic kidney failure }\end{array}$ & $\begin{array}{l}12(24.5) \\
7(14.3) \\
1(2.0) \\
0 \\
4(8.2)\end{array}$ & $\begin{array}{l}7(31.8) \\
4(18.1) \\
0 \\
0 \\
3(13.6)\end{array}$ & $\begin{array}{l}5(18.1) \\
3(11.1) \\
1(3.7) \\
0 \\
1(3.7)\end{array}$ & 0.41 \\
\hline $\begin{array}{l}\text { Alcohol abuse } \\
\text { Tobacco, cumulative exposure, mean (SD) (year) } \\
\mathrm{BMI}^{\mathrm{b}} \text {, median }\left(\mathrm{IQR}^{\mathrm{c}}\right), \mathrm{kg} / \mathrm{m}^{2} \\
\text { Undernutrition }^{\mathrm{d}}, \mathrm{n}(\%)\end{array}$ & $\begin{array}{l}2(4.0) \\
13.6(20.5) \\
26.0(22.0-31.0) \\
7(14.3)\end{array}$ & $\begin{array}{l}1(4.5) \\
14.5(17.8) \\
24.0(20.5-30.0) \\
6(28.6)\end{array}$ & $\begin{array}{l}1(3.7) \\
12.7(23.2) \\
28.4(23.0-32.0) \\
1(4.2)\end{array}$ & $\begin{array}{l}0.17 \\
0.12\end{array}$ \\
\hline $\begin{array}{l}\text { ASA score }^{\mathrm{e}}, \mathrm{n}(\%) \\
1 \\
2 \\
3 \\
4\end{array}$ & $\begin{array}{l}15(30.6) \\
21(42.9) \\
13(26.5) \\
0\end{array}$ & $\begin{array}{l}5(22.7) \\
8(36.4) \\
9(40.9) \\
0\end{array}$ & $\begin{array}{l}10(37.0) \\
13(48.1) \\
4(14.8) \\
0\end{array}$ & 0.12 \\
\hline Number of previous infections, mean $\left(\mathrm{SD}^{\dagger}\right)$, day & $0.67(0.8)$ & $0.86(1.0)$ & $0.52(0.6)$ & 0.26 \\
\hline 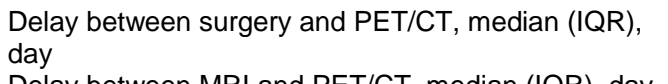 & $256(153-682)$ & $413(166-1346)$ & $197(148-534)$ & 0.07 \\
\hline $\begin{array}{l}\text { Delay between MRI and PET/CT, median (IQR), day } \\
\text { Duration of follow-up after PET/CT, median (IQR), } \\
\text { day }\end{array}$ & $\begin{array}{l}8.0(0-43) \\
412(187-971)\end{array}$ & $\begin{array}{l}26.5(2-49) \\
416(214-755)\end{array}$ & $\begin{array}{l}3.5(0-37) \\
409(153-1244)\end{array}$ & $\begin{array}{l}0.15 \\
0.87\end{array}$ \\
\hline \multicolumn{5}{|l|}{ Surgical characteristics } \\
\hline $\begin{array}{l}\text { Reason for surgery, } \mathbf{n}(\%) \\
\text { Traumatic } \\
\text { Degenerative } \\
\text { Scoliosis }\end{array}$ & $\begin{array}{l}2(4.1) \\
36(73.5) \\
11(22.4)\end{array}$ & $\begin{array}{l}0(0.0) \\
14(63.6) \\
8(36.4)\end{array}$ & $\begin{array}{l}2(7.4) \\
22(81.5) \\
3(11.1)\end{array}$ & 0.06 \\
\hline Number of previous surgery, mean (SD) & $2.6(2.9)$ & $2.9(4.2)$ & $2.4(1.4)$ & 0.56 \\
\hline $\begin{array}{l}\text { Location, } \mathbf{n}(\%) \\
\text { Cervical } \\
\text { Thoracic } \\
\text { Lumbar } \\
\text { Thoraco-lumbar } \\
\text { Thoraco-lumbo-sacral } \\
\text { Cervico-thoraco-lumbo-sacral } \\
\text { Lumbo-sacral }\end{array}$ & $\begin{array}{l}4(8.2) \\
0 \\
19(38.8) \\
3(6.1) \\
6(12.2) \\
4(8.2) \\
13(26.5)\end{array}$ & $\begin{array}{l}1(4.5) \\
0 \\
10(45.5) \\
2(9.1) \\
2(9.1) \\
3(13.6) \\
4(18.2)\end{array}$ & $\begin{array}{l}3(11.1) \\
0 \\
9(33.3) \\
1(3.7) \\
4(14.8) \\
1(3.7) \\
9(33.3)\end{array}$ & 0.48 \\
\hline $\begin{array}{l}\text { Number of fused levels, } \mathbf{n}(\%) \\
\leq 2 \\
\geq 3\end{array}$ & $\begin{array}{l}21(42.9) \\
28(57.1)\end{array}$ & $\begin{array}{l}8(36.4) \\
14(63.6)\end{array}$ & $\begin{array}{l}13(48.1) \\
14(51.9)\end{array}$ & 0.41 \\
\hline $\begin{array}{l}\text { Surgical approach, } \mathbf{n}(\%) \\
\text { Anterior } \\
\text { Posterior }\end{array}$ & $\begin{array}{l}4(8.2) \\
45(91.8)\end{array}$ & $\begin{array}{l}1(4.5) \\
21(96.4)\end{array}$ & $\begin{array}{l}3(11.1) \\
24(88.9)\end{array}$ & 0.40 \\
\hline $\begin{array}{l}\text { Type of surgery, } \mathbf{n}(\%) \\
\text { Arthrodesis }+ \text { intersomatic cage(s) } \\
\text { Disk prosthesis } \\
\text { Arthrodesis without intersomatic cage }\end{array}$ & $\begin{array}{l}22(44.9) \\
1(2.0) \\
26(53.0)\end{array}$ & $\begin{array}{l}7(31.8) \\
1(4.5) \\
14(63.6)\end{array}$ & $\begin{array}{l}15(55.6) \\
0 \\
12(44.4)\end{array}$ & 0.31 \\
\hline $\begin{array}{l}\text { Type of material, } \mathbf{n}(\%) \\
\text { Metal } \\
\text { Metal + PEEK } \\
\text { Metal + bone substitute and bone graft }\end{array}$ & $\begin{array}{l}25(51.0) \\
12(24.5) \\
12(24.5)\end{array}$ & $\begin{array}{l}15(68.2) \\
4(18.2) \\
3(13.6)\end{array}$ & $\begin{array}{l}10(37.0) \\
8(29.6) \\
9(33.3)\end{array}$ & 0.08 \\
\hline $\begin{array}{l}\text { Biological characteristics } \\
\text { C-reactive protein, mean (SD) mg/L } \\
\text { Glycemia, mean (SD) g/L }\end{array}$ & $\begin{array}{l}45.3(72.8) \\
0.98(0.16)\end{array}$ & $\begin{array}{l}84.8(92.6) \\
0.95(0.12)\end{array}$ & $\begin{array}{l}13.1(21.1) \\
1.0(0.18)\end{array}$ & $\begin{array}{l}0.001 \\
0.54\end{array}$ \\
\hline Creatinine, mean (SD) $\mu \mathrm{mol} / \mathrm{L}$ & $71.0(19.5)$ & $73.0(27.0)$ & $69.0(17.0)$ & 0.39 \\
\hline $\begin{array}{l}\text { White blood cell, mean (SD) G/L } \\
\text { Blood polymorphonuclear neutrophil, mean (SD) G/L }\end{array}$ & $\begin{array}{l}8.2(2.7) \\
5.4(2.3)\end{array}$ & $\begin{array}{l}8.7(2.6) \\
6.2(2.2)\end{array}$ & $\begin{array}{l}7.7(2.8) \\
4.8(2.2)\end{array}$ & $\begin{array}{l}0.11 \\
0.03\end{array}$ \\
\hline
\end{tabular}


Table 2: diagnostic values for the different diagnostic methods

\begin{tabular}{lccccc}
\hline MRI & CRP $\geq 60$ mg/L & $\begin{array}{c}\text { Semi- } \\
\text { quantitative } \\
\text { PET/CT }\end{array}$ & $\begin{array}{c}\text { Visual } \\
\text { PET/CT }\end{array}$ & $\begin{array}{c}\text { Visual } \\
\text { PET/CT - CRP } \\
\text { combined } \\
\text { evaluation }\end{array}$ \\
\hline $\begin{array}{l}\text { Sensitivity } \\
(\%)\end{array}$ & 66.7 & 50.0 & 40.9 & 86.4 & 90.9 \\
$\begin{array}{l}\text { Specificity } \\
\text { (\%) }\end{array}$ & 75.0 & 92.6 & 85.2 & 81.5 & 77.8 \\
PPV (\%) & 66.0 & 84.6 & 69.2 & 79.2 & 76.9 \\
NPV (\%) & 75.0 & 69.4 & 63.9 & 88.0 & 91.3 \\
Accuracy & 71.4 & 73.4 & 65.3 & 83.7 & 83.7 \\
AUC & 0.71 & 0.71 & 0.63 & 0.84 & 0.84 \\
(95\% Cl) & $(0.57-0.85)$ & $(0.56-0.86)$ & $(0.47-0.79)$ & $(0.73-0.95)$ & $(0.73-0.95)$ \\
p-value & 0.16 & 0.09 & 0.001 & $-(r e f)$ & 0.88 \\
\hline
\end{tabular}

MRI: magnetic resonance imaging; PET/CT: positron emission tomography/computed tomography; CRP: Creactive protein; PPV: positive predictive value; NPV: negative predictive value; AUC: area under the curve; $\mathrm{Cl}$ : confidence interval; $p$-value refers to the comparison by ROC curve of the different exams to the visual analysis of $\mathrm{PET} / \mathrm{CT}$.

\#Patients with positive visual PET/CT or CRP $\geq 60 \mathrm{mg} / \mathrm{L}$ were considered as having a positive evaluation. 
Table 3: diagnostic values of visual PET/CT according to the number of fused levels

\begin{tabular}{lcccc}
\hline & $\begin{array}{c}\mathbf{1} \\
(\mathrm{n}=\mathbf{1 3})\end{array}$ & $\begin{array}{c}\mathbf{2} \\
(\mathrm{n}=\mathbf{8})\end{array}$ & $\begin{array}{c}\mathbf{2 3} \\
(\mathrm{n}=\mathbf{2 8})\end{array}$ & $\begin{array}{c}\text { All levels } \\
(\mathrm{n}=\mathbf{4 9})\end{array}$ \\
\hline Sensitivity (\%) & 100 & 100 & 79 & 86 \\
Specificity (\%) & 100 & 75 & 64 & 81 \\
PPV (\%) & 100 & 80 & 69 & 79 \\
NPV (\%) & 100 & 100 & 75 & 88 \\
\hline
\end{tabular}

PET/CT: positron emission tomography/computed tomography; PPV: positive predictive value; NPV: negative predictive value 

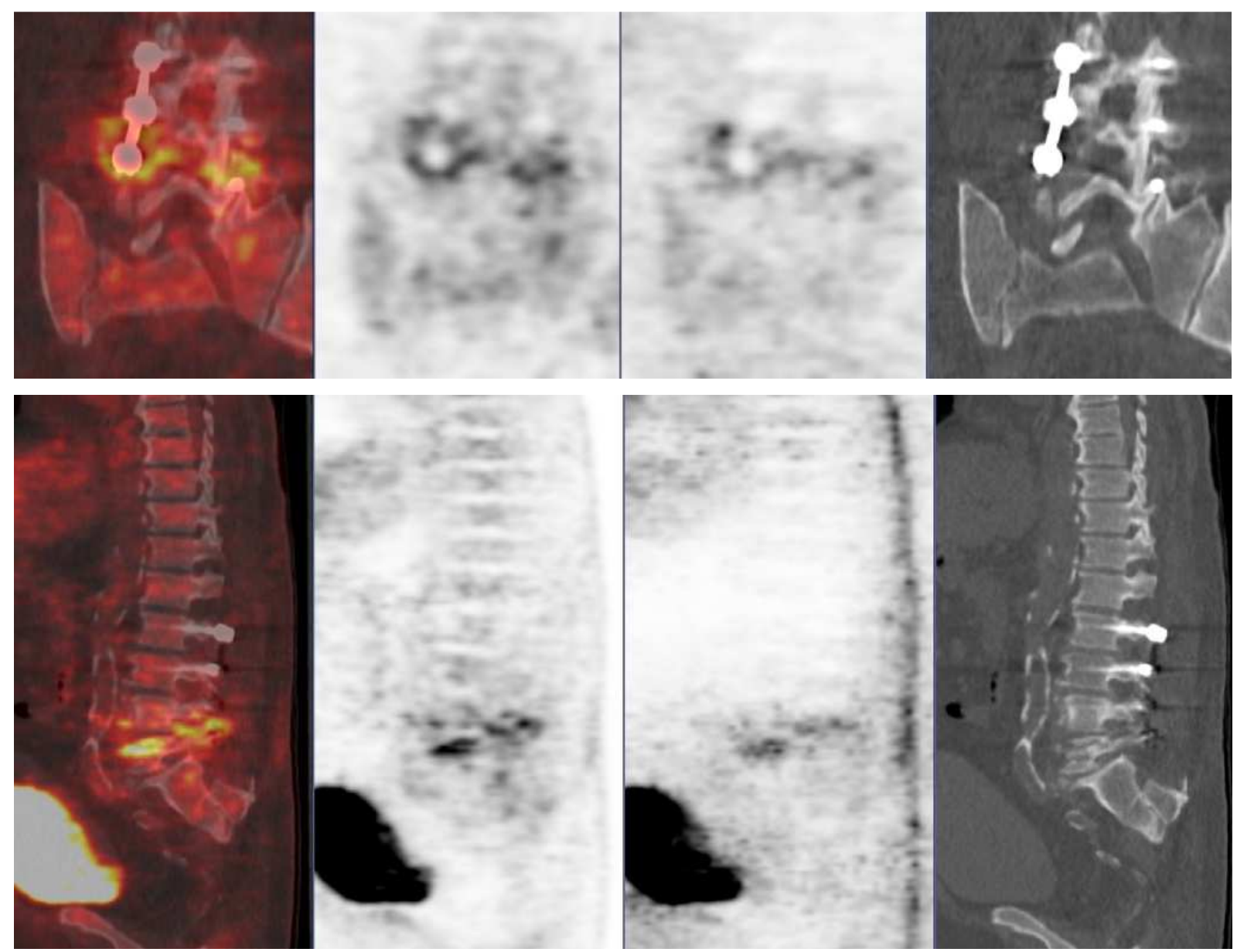

Figure 1: PET/CT's patient who presented a lumbar arthrodesis infection. Left to right: fusion, attenuation correction (AC), non-attenuation correction (NAC) and CT. Hypermetabolism concentrated next to the screw. 